\title{
Functional characterization of peripheral blood dendritic cells and monocytes in systemic lupus erythematosus
}

\author{
Ana Henriques - Luís Inês - Tiago Carvalheiro - Maura Couto • \\ Ângela Andrade · Susana Pedreiro · Paula Laranjeira · José Mário Morgado • \\ Maria Luísa Pais · José António Pereira da Silva $\cdot$ Artur Paiva
}

Received: 13 May 2010/ Accepted: 18 December 2010

(C) Springer-Verlag 2011

\begin{abstract}
With the purpose of contributing to a better knowledge of the APCs functional activity in SLE, we evaluated the distribution and functional ability to produce pro-inflammatory cytokines (TNF- $\alpha$, IL-1 $\beta$, IL-6 and IL12) of peripheral blood (PB) monocytes and $\mathrm{DC}(\mathrm{tDC})$, particularly myeloid $(\mathrm{mDC})$ and $\mathrm{CD} 14^{-/ \mathrm{low}} \mathrm{CD} 16^{+} \mathrm{DC}$ subpopulations comparing them with those obtained from healthy individuals. The study was performed in 34 SLE patients with diverse disease activity scores (SLEDAI) and 13 healthy age- and sex-matched controls (NC). Our results show an overall decrease in absolute number and relative frequency of tDC in SLE patients with active disease when compared to those with inactive disease and $\mathrm{NC}$, although this decrease did not seem to have an effect on the distribution of PB DC subsets. The monocytes number in SLE patients was similar to those found in NC, whereas a higher frequency of monocytes producing cytokines as well as the amount of each cytokine per cell found without stimulation was particularly observed in those patients with active disease. After stimulation, we observed a higher frequency
\end{abstract}

A. Henriques, L. Inês and T. Carvalheiro are contributed equally to this work.

A. Henriques $\cdot$ T. Carvalheiro $\cdot$ S. Pedreiro $\cdot$ P. Laranjeira $\cdot$

J. M. Morgado - M. L. Pais · A. Paiva $(\square)$

Centro de Histocompatibilidade do Centro, Edifício São

Jerónimo, $4^{\circ}$ Piso, Praceta Mota Pinto, 3001-301 Coimbra,

Portugal

e-mail: apaiva@histocentro.min-saude.pt

L. Inês · M. Couto · J. A. P. da Silva

Rheumatology Service of HUC, Coimbra, Portugal

Â. Andrade · A. Paiva

Superior School of Health Technology of Coimbra, Coimbra, Portugal of IL-12-producing monocytes in active SLE patients. On the other hand, we found among DCs higher frequencies of cytokine-producing $\mathrm{CD} 14^{-/ \mathrm{low}} \mathrm{CD} 16^{+} \mathrm{DCs}$ and a higher amount of cytokines produced per cell, particularly in active disease. These findings support an increased production of inflammatory cytokines by APCs in active SLE, mostly associated with alterations in $\mathrm{CD} 14^{-/ \mathrm{low}} \mathrm{CD} 16^{+} \mathrm{DC}$ subset homeostasis that might contribute to explain the dynamic role of these cells in disease pathogenesis.

Keywords Dendritic cells · Monocytes · Inflammatory cytokines $\cdot$ Systemic lupus erythematosus

\section{Introduction}

SLE is a multiorgan system autoimmune disease with numerous immunological and clinical manifestations [1]. It is characterized by a large amount of circulating autoantibodies (autoAb) with diverse specificities as a result of abnormal activation of autoreactive B- and T-helper lymphocytes $[2,3]$. The abnormal function of $\mathrm{T}$ cells may result from underlying defects in APC function. Actually, despite attention primarily focused on the role of $\mathrm{B}$ and $\mathrm{T}$ cells in SLE pathogenesis, there are growing evidences for dysfunctional professional APCs in autoimmunity [4-6]. Among them, monocytes/macrophages are versatile cells aiming to defend, regulate inflammation, and induce immunity [7]. Furthermore, circulating monocytes are recruited to sites of inflammation where they become activated and differentiate further into resident tissue macrophages specialized in phagocytosis and subsequent antigen presentation [8]. In this sense, an active role in mediating tissue inflammation and injury is engaged by monocytes with well-developed secretory functions. Experimental 
evidences suggest that monocytes differentiate also into DCs in vivo $[9,10]$. However, the differentiation of DCs from a pre-monocyte precursor or monocytes remains controversial. Accordingly, at present, it is well established that DC is not a homogeneous cell population, and at least three different DC subsets have been described in normal human peripheral blood $(\mathrm{PB})[11,12]$. One defined as $\mathrm{CD} 123^{\mathrm{dim}} /$ $\mathrm{CD}^{-} 6^{-}$myeloid DC subpopulation $(\mathrm{mDC})$, strongly expressing HLA-DR and the myeloid-associated antigens $\mathrm{CD} 11 \mathrm{c}$ and CD33. Another defined as $\mathrm{CD} 33^{-/ \mathrm{dim}} / \mathrm{CD} 16^{-}$ lymphoplasmacytoid subpopulation (pDC), strongly expressing HLA-DR and CD123. A third one is a CD14 $4^{-/ \text {low } / ~}$ $\mathrm{CD} 123^{\text {inter }} / \mathrm{CD} 33^{\text {inter }} / \mathrm{CD} 16^{+}$monocyte-related subpopulation $\left(\mathrm{CD} 14^{-/ \mathrm{low}} \mathrm{CD} 16^{+} \mathrm{DC}\right)$ initially described as a minor subset of mature monocytes [13-15]. Accordingly, this latter DC subpopulation seems to display intermediate features between a PB monocyte and DC, such as a high expression of $\mathrm{Fc} \gamma \mathrm{RIII}(\mathrm{CD} 16)$, a relatively low activity as APC in comparison with other peripheral blood DC and a high ability to generate in vitro activation of naive $\mathrm{T}$ cells.

DCs are the most central player in all immune responses, both innate and adaptive, being exceptionally potent immunogenic under inflammatory conditions, yet are also critical to the induction and maintenance of self-tolerance in the steady state [16-18]. In this sense, emergent data suggest that DCs heterogeneity and activation states may be involved in autoimmune response either by a dysregulation of DC maturation towards their chronic activation and their cytokine secretion or by defective induction and maintenance of antigen-specific peripheral T-cell tolerance. Thus, abnormalities reported in SLE patients may represent DC-intrinsic defects and/or result of secondary defects such an imbalance of cytokine signals that could generate directly prime of autoreactive $\mathrm{T}$ cells, or fail to prime regulatory $\mathrm{T}$-cell subsets, or even shift a Th1/Th2 balance to an unfavourable outcome [19-23].

To gain better insight into the pathogenesis of SLE, we investigated the frequency of PB monocytes and DC subsets as well as their functional characteristics to comparatively explore in these cell subsets their differential ability to produce cytokines according to the status of disease.

\section{Patients and methods}

Patients

We recruited patients with SLE fulfilling the 1997 ACR classification criteria for the disease [24, 25]. All patients were followed at the Rheumatology Department of the University Hospital of Coimbra, Portugal. The disease activity at time of evaluation was classified according to the Systemic Lupus Erythematosus Disease Activity Index
(SLEDAI 2000) [26, 27]. Patients were divided into two groups, one with active (SLEDAI $\geq 5 ; n=15$ ) and the other with inactive SLE (SLEDAI $<5 ; n=19$ ) [28]. Medication at time of evaluation was recorded.

\section{Controls}

As controls, we recruited 13 healthy age- and gendermatched bone marrow donors (NC group) $(76.9 \%$ female, mean age $34 \pm 10$ years; range $25-54$ years) at the Histocompatibility Center of Coimbra. Pregnancy and age under 18 were exclusion criteria for participation. The local ethics committee approved study protocol. All participants gave and signed informed consent.

In vitro stimulation of cytokine production by DCs and monocytes

A total of $500 \mu \mathrm{l}$ of each PB sample was diluted 1/l (vol/ vol), in duplicate, in RPMI-1640 medium (Gibco; Paisley, Scotland, UK), supplemented with $2 \mathrm{mM}$ L-glutamine and incubated at $37^{\circ} \mathrm{C}$ in a sterile environment with a $5 \% \mathrm{CO} 2$ humid atmosphere for $6 \mathrm{~h}$, in the presence of $10 \mu \mathrm{g} / \mathrm{ml}$ of Brefeldin A (Sigma, St. Louis, MO) to prevent the release of cytokines outside the cells. In addition, $100 \mathrm{ng} / \mathrm{ml}$ of lipopolysaccharide (LPS) from Escherichia coli [serotype 055:B5 (Sigma)] plus $100 \mathrm{U} / \mathrm{ml}$ of interferon- $\gamma$ (IFN- $\gamma$ ); Promega, Madison, WI) were added to one of the tubes (stimulated samples). The other tube was used as a control.

Immunofluorescent staining

After this incubation period, both stimulated and the unstimulated samples were aliquoted in different tubes (200 $\mu \mathrm{l} /$ tube) in order to analyse the expression of each cytokine under study, by monocytes and DCs subsets.

In order to identify DC subsets, a Dendritic Cell Exclusion Kit-flourescein isothiocyanate (FITC) (Cytogonos, Salamanca, Spain)—combined with anti-HLA-DR-peridin chlorophyll protein (PerCP) (clone L243; BDB, San Jose, USA) - and anti-CD33-allophycocyanin (APC) (clone P67.6; BDB, San Jose, USA) —was added to each tube. After gentle mixing, cells were sequentially incubated for $15 \mathrm{~min}$ at room temperature, in the darkness and washed once in with $2 \mathrm{ml}$ of phosphate-buffered saline (PBS, Dulbecco 1x, Biochrom AG, Berlin, Germany), (5 min at $540 \times \mathrm{g}$ ). After discarding the supernatant, cells were fixed and permeabilized with FIX\&PERM (Caltag, Hamburg, Germany) according to manufacturer's instructions and stained with PE-conjugated $\mathrm{mAb}$ directed against different human intracytoplasmic cytokines: anti-interleukin (IL)- $1 \beta$ (clone AS10; BDB, San Jose, USA), anti-IL-6 (clone MQ26A; Pharmingen, San Diego, USA), anti-IL-12 (clone 
C11.5; Pharmingen, San Diego, USA) and anti-tumour necrosis factor (TNF)- $\alpha$ (clone Mab11; Pharmingen, San Diego, USA). Each anti-cytokine mAb reagent was placed in a separate tube containing either the stimulated or the unstimulated sample. The tubes were incubated for $15 \mathrm{~min}$ at room temperature in the darkness. Then, cells were washed twice with $2 \mathrm{ml}$ of PBS ( $5 \mathrm{~min}$ at $540 \times \mathrm{g}$ ) and resuspended in $0.5 \mathrm{ml}$ of PBS until they were analysed in a flow cytometer.

Flow cytometry data acquisition and analysis

The data acquisition was performed in two consecutive steps in a FACSCalibur flow cytometer (BDB, San Jose, USA) equipped with an argon ion laser and a red diode laser. In a first step, $2 \times 10^{4}$ events, corresponding to all nucleated cells present in the sample, were collected and information on them stored. In a second step, information was stored exclusively for those cells included in a live gate containing $\mathrm{HLA}_{-} \mathrm{DR}^{+}$events, in a minimum of $2 \times 10^{5}$ events. Absolute counts were calculated using a dual platform methodology (flow cytometry and haematological cell analyser).

\section{Statistical analysis}

Statistical evaluation of data were analysed using the nonparametric Mann-Whitney $U$ test. Results were expressed as the mean $\pm \mathrm{SD}$, median. All statistical analyses were performed using SPSS Inc, Chicago, USA, and differences were considered as statistically significant when the $P$ value was less than 0.05 .

\section{Results}

SLE patients with active and inactive disease

Forty-seven subjects were enrolled in the study, comprising thirty-four SLE patients, fifteen with active disease $(86.7 \%$ female, mean age $32 \pm 11$ years; range $22-48$ years) and nineteen with inactive disease $(89.5 \%$ female, mean age $34 \pm 9$ years; range 24-54 years). Mean SLEDAI scores in the active SLE and inactive SLE group were $10.3 \pm 3.53$ and $2.7 \pm 1.52$, respectively. The time since diagnosis was $9 \pm 5$ years in both groups. Lupus nephritis was the most prevalent major organ involvement, diagnosed in $66.7 \%$ of active SLE and $52.6 \%$ of inactive SLE cases. Three patients had neurolupus, all from the inactive SLE group. Prevalence of lupus arthritis was $93.3 \%$ in the active SLE group and $68.4 \%$ in the inactive SLE group. Haematological involvement was present in $93.3 \%$ of active SLE and in $84.2 \%$ of inactive SLE group patients. Lupus skin disease was found in $80 \%$ of active SLE and $52.6 \%$ of inactive SLE patients. At the time of evaluation, patients with active SLE and inactive SLE, respectively, were receiving treatment with hydroxychloroquine in 80 and $94.7 \%$ of cases, prednisone 93.3 and $42.1 \%$ (mean daily dose 18.2 and $5.3 \mathrm{mg}$ ) and immunossupressants (micofenolate mofetil, azatioprine or cyclosporine) in 53.3 and $31.6 \%$, respectively.

Frequency of monocytes, $t D C s$ and their $m D C, p D C$ and $\mathrm{CD} 14^{- \text {llow }} \mathrm{CD} 16^{+}$DC subpopulations in SLE and healthy subjects

DCs were identified by the combined expression of CD33 and HLA-DR and absence of CD14, CD19, CD56 and CD3 with intermediate forward (FSC) and side scatter (SSC) between those of lymphocytes and monocytes (Fig. 1a, b, c). Based on the expression of CD33 and HLA-DR, we could identify three subpopulations of DCs: a subset of CD $123^{\text {dim }} / \mathrm{CD} 33^{\text {high }} / \mathrm{CD} 16^{\text {neg }}$ cells, with strong expression of HLA-DR-mDCs; a subset of $\mathrm{CD} 123^{\text {inter }} / \mathrm{CD} 33^{\text {inter/ }}$ CD $16^{\text {pos }}-\mathrm{CD} 14^{-/ \text {low }} \mathrm{CD} 16^{+}$DCs and other of CD $123^{\text {high/ }}$ $\mathrm{CD} 33^{\text {neg/dim }} / \mathrm{CD} 16^{\text {neg }}$ cells-pDCs, both with intermediate expression of HLA-DR (Fig. 1d, e, f, g). We identified monocytes as expressing CD33, CD14 and HLA-DR and by their FSC and SSC characteristics.

As shown in Table 1, frequency and absolute numbers (cell/ $\mu \mathrm{l}$ ) of PB DCs were lower in both SLE groups than in control group, reaching statistical significance in those patients with active disease $(P<0.05)$. In contrast, no significant differences were found in the proportion and absolute numbers of circulating monocyte or in proportions of the three characterized DC subsets among tDC (Table 1).

Cytokine production by PB monocytes from SLE patients and healthy subjects

Without stimulation with LPS plus IFN- $\gamma$ active and inactive SLE presented a higher frequency of monocytes producing IL-6 and TNF- $\alpha$ when compared with control group (Table 2). Moreover in active SLE, we found a significant increase in the frequency of monocytes producing IL-1 $\beta \quad(P<0.05)$. After stimulation, we only observed in active SLE a higher frequency of monocytes producing IL-12 $(P<0.05)$, and no significant differences were found between the studied groups with respect to the amount of cytokine produced per cell (Table 2).

Cytokine production by PB DC subsets from SLE patients and healthy subjects

We evaluated the production of IL- $1 \beta$, IL-6, IL-12 and TNF- $\alpha$ by mDCs and CD16 ${ }^{+}$DCs at basal level and after $6 \mathrm{~h}$ of stimulation with LPS and IFN- $\gamma$. 

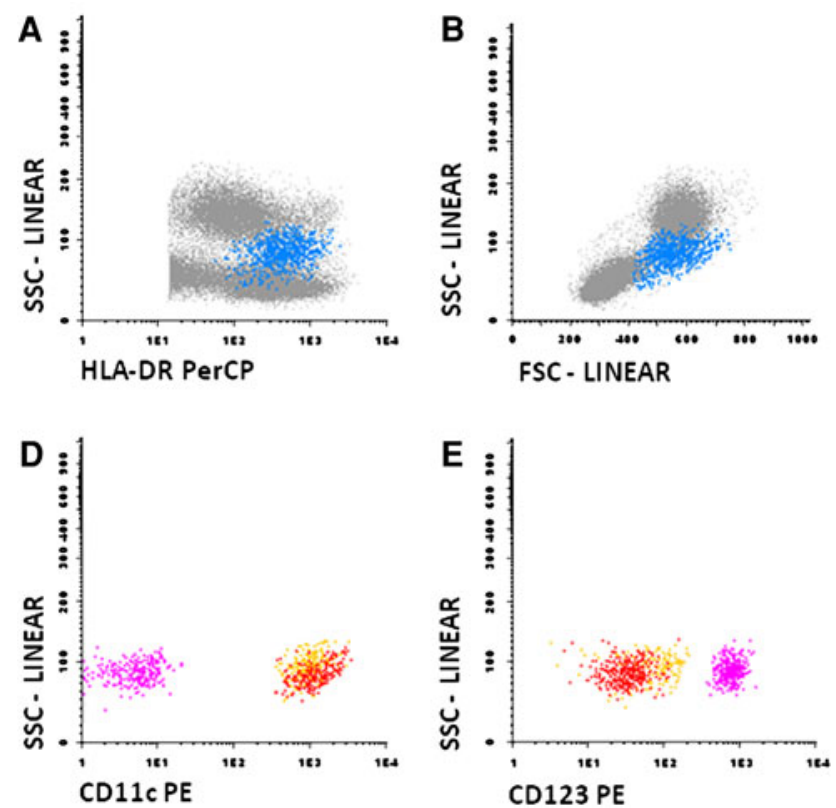

Fig. 1 Representative bivariate dot plots illustrating how DCs (a, $\mathbf{b}$ and $\mathbf{c}$ ) and their subsets (d, e, f, and $\mathbf{g}$ ) were identified in PB using a mixture of FITC-conjugated anti-CD3, CD56, CD19 and CD14 mAbs combined with anti-HLA-DR PerCP, CD33 APC and CD16 PE:

Table 1 Comparative analysis of overall monocytes, DCs and their subsets frequencies (percentage; cells number/ $\mu \mathrm{L}$ of $\mathrm{PB}$ ) in SLE and control groups

\begin{tabular}{lccc}
\hline & Active SLE & Inactive SLE & Control group \\
\hline$\%$ of $\mathrm{DCs}$ & $0.2 \pm 0.1^{*}$ & $0.3 \pm 0.2$ & $0.5 \pm 0.1$ \\
$\mathrm{DCs} / \mu \mathrm{L}$ & $42.4 \pm 28.8$ & $59.8 \pm 21.1$ & $56.9 \pm 10.7$ \\
$\%$ of $\mathrm{mDCs}$ & $33.6 \pm 15.4$ & $38.4 \pm 51.1$ & $39.7 \pm 18.0$ \\
$\mathrm{mDCs} / \mu \mathrm{L}$ & $13.2 \pm 9.5$ & $25.3 \pm 25.4$ & $22.5 \pm 11.1$ \\
$\%$ of $\mathrm{CD} 16^{+} \mathrm{DCs}$ & $39.4 \pm 21.8$ & $36.3 \pm 15.7$ & $38.4 \pm 18.9$ \\
$\mathrm{CD} 16^{+} \mathrm{DCs} / \mu \mathrm{L}$ & $18.3 \pm 19.8$ & $24.3 \pm 26.9$ & $21.8 \pm 11.2$ \\
$\%$ of $\mathrm{pDCs}$ & $26.0 \pm 13.2$ & $25.2 \pm 13.5$ & $21.7 \pm 12.1$ \\
$\mathrm{pDC} / \mu \mathrm{L}$ & $8.5 \pm 4.0$ & $12.6 \pm 9.7$ & $15.2 \pm 8.8$ \\
$\%$ of monocytes & $3.2 \pm 1.6$ & $3.8 \pm 1.6$ & $3.5 \pm 0.8$ \\
Monocytes $/ \mu \mathrm{L}$ & $484 \pm 170.0$ & $628.2 \pm 443.2$ & $443.9 \pm 116.3$ \\
\hline
\end{tabular}

The percentages presented for DC subsets were obtained among total DCs

Results expressed as mean percentage \pm standard deviation

Statistically significant differences were considered when $P<0.05$ (Mann-Whitney $U$ test): *Active SLE versus control group

Without stimulation, we observed in all studied groups a lower percentage of cytokine-producing $\mathrm{mDCs}$ and CD $14^{- \text {llow }} \mathrm{CD} 16^{+}$DCs (always below 2\%-data not shown), and therefore this results were not considered.

After in vitro stimulation, we observed a higher frequency of $\mathrm{CD} 14^{-/ \mathrm{low}} \mathrm{CD} 16^{+}$DCs producing all studied cytokines from both SLE groups compared to NC $(P<0.05)$, which was more evident in active SLE group

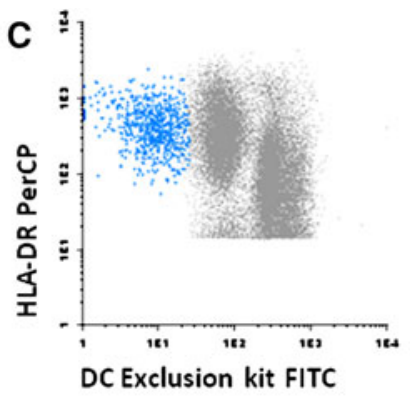

Blue - total Dendritic Cells Red - mDC

Yellow - CD $14^{-/ 10 w} \mathrm{CD} 16^{+} \mathrm{DC}$

Pink - pDC
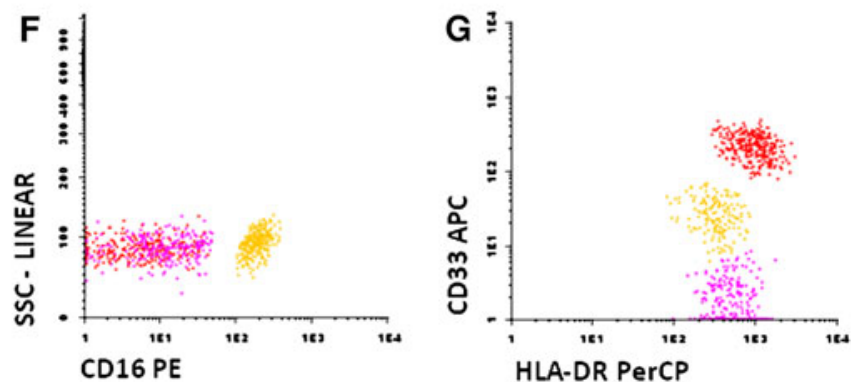

mDC-CD $123^{\text {dim }} / \mathrm{CD} 33^{\text {high }} / \mathrm{CD} 16^{\text {neg }} / \mathrm{CD} 11^{\text {hight }} ; \mathrm{CD} 14^{-/ \text {low }} \mathrm{CD} 16^{+} \mathrm{DC}-$ $\mathrm{CD} 123^{\text {inter }} / \mathrm{CD} 33^{\text {inter }} / \mathrm{CD} 16^{\text {pos }} / \mathrm{CD} 11 \mathrm{c}^{\text {pos }} ; \mathrm{pDC}-\mathrm{CD} 123^{\text {high }} / \mathrm{CD} 33^{\text {neg/dim}} /$ $\mathrm{CD} 16^{\text {neg }} / \mathrm{CD} 11 \mathrm{c}^{\text {neg }}$

(Fig. 2). In line with these findings, a statistical significant increase was reached for $\mathrm{IL}-1 \beta$-producing $\mathrm{CD} 14^{- \text {low }}$ $\mathrm{CD}^{+} 6^{+}$DCs between active and inactive SLE groups $(P<0.05)$. In contrast, the frequencies of cytokine-producing mDCs were similar in the three groups (Table 3 ).

When we analysed the amount of each studied cytokine at single cell level, there was a notably increased expression of all cytokines in $\mathrm{CD} 14^{-/ \text {low }} \mathrm{CD} 16^{+} \mathrm{DCs}$ from active and inactive SLE patients compared to healthy subjects $(P<0.05)$ (Fig. 2). In addition, regarding $\mathrm{mDCs}$, we observed a lower amount of TNF- $\alpha$ per cell in inactive SLE group compared to NC $(P<0.05)$ (Table 3$)$, without other significant differences between the three studied groups.

\section{Discussion}

The overexpression of chemokines and homeostasis imbalance of APC, including DC, has been proposed in the development of SLE [29-31], but the potential role of those cells in disease pathogenesis is far from clear. With this study, it was our aim to comparatively analyse the functional characteristics of those cells from SLE patients and from normal controls in order to clarify their role in the disease pathogenesis.

Our results showed that although the number of tDCs in SLE patients, particularly in those with active disease was significantly decreased, only slight alterations were detected in the relative proportion of the three DC subtypes 
Table 2 Frequency of monocytes producing TNF- $\alpha$, IL-1 $\beta$, IL-6 and IL-12 and amount of each cytokine per cell with and without stimulation with LPS plus IFN- $\gamma$ in the three studied groups

\begin{tabular}{|c|c|c|c|c|c|c|}
\hline & \multicolumn{2}{|l|}{ Active SLE } & \multicolumn{2}{|l|}{ Inactive SLE } & \multicolumn{2}{|l|}{ Control } \\
\hline & $\%$ & MFI & $\%$ & MFI & $\%$ & MFI \\
\hline \multicolumn{7}{|l|}{$\mathrm{IL}-1 \beta$} \\
\hline No stimulus & $11.1 \pm 12.8^{\mathrm{a}}$ & $29.7 \pm 5.5$ & $6.0 \pm 10.1$ & $29.7 \pm 12.2$ & $<3.00$ & N.D. \\
\hline LPS + IFN $-\gamma$ stimulus & $94.5 \pm 5.7$ & $83.6 \pm 23.6$ & $87.3 \pm 18.0$ & $92.0 \pm 45.5$ & $84.6 \pm 24.1$ & $104.8 \pm 37.7$ \\
\hline \multicolumn{7}{|l|}{ IL-6 } \\
\hline No stimulus & $8.9 \pm 9.0^{\mathrm{a}}$ & $31.5 \pm 7.9$ & $6.5 \pm 11.1^{\mathrm{b}}$ & $29.4 \pm 17.8$ & $<3.00$ & N.D. \\
\hline LPS + IFN- $\gamma$ stimulus & $86.2 \pm 13.2$ & $118.6 \pm 51.8$ & $84.3 \pm 13.4$ & $118.6 \pm 49.4$ & $73.9 \pm 34.6$ & $106.3 \pm 51.1$ \\
\hline \multicolumn{7}{|l|}{ IL-12 } \\
\hline No stimulus & $4.6 \pm 9.4$ & $27.2 \pm 3.8$ & $<3.00$ & N.D. & $<3.00$ & N.D. \\
\hline LPS + IFN $-\gamma$ stimulus & $31.5 \pm 35.5^{\mathrm{a}}$ & $33.8 \pm 14.4$ & $10.5 \pm 13.6$ & $30.7 \pm 4.8$ & $5.9 \pm 6.1$ & $39.1 \pm 8.1$ \\
\hline \multicolumn{7}{|l|}{ TNF- $\alpha$} \\
\hline No stimulus & $9.7 \pm 12.8^{\mathrm{a}}$ & $70.3 \pm 67.2$ & $4.7 \pm 6.8^{\mathrm{b}}$ & $61.5 \pm 85.4$ & $<3.00$ & N.D. \\
\hline LPS + IFN $-\gamma$ stimulus & $85.8 \pm 15.3$ & $645.8 \pm 443.1$ & $87.0 \pm 7.7$ & $583.6 \pm 268.4$ & $81.6 \pm 21.5$ & $800.2 \pm 640.6$ \\
\hline
\end{tabular}

$\%$ Percentage of positive cells; MFI mean fluorescence intensity of positive cells. Results expressed as mean percentage \pm standard deviation Statistically significant differences were considered when $P<0.05$ (Mann-Whitney $U$ test): ${ }^{a}$ Active SLE versus Control; ${ }^{b}$ Inactive SLE versus Control
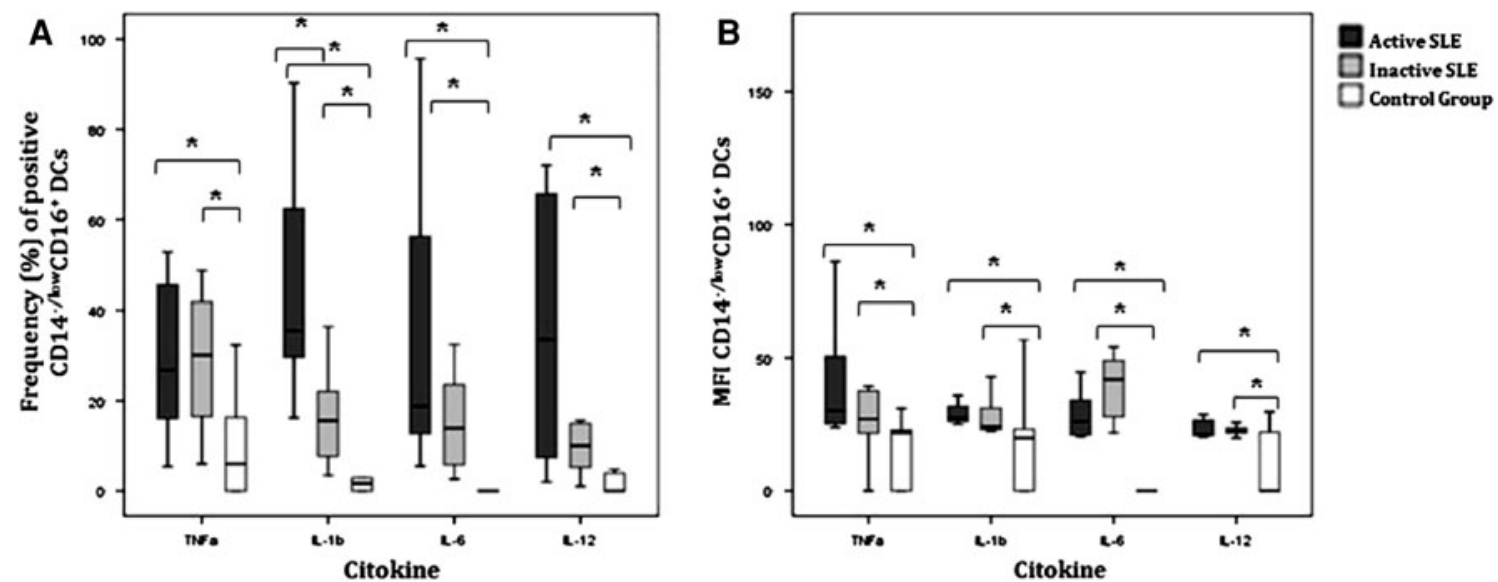

Fig. 2 Frequency of $\mathrm{CD} 14^{-/ \text {low }} \mathrm{CD} 16^{+}$DCs producing TNF- $\alpha$, IL-1 $\beta$, IL-6 and IL-12 and amount of each cytokine per cell after stimulation with LPS plus IFN- $\gamma$ in the three studied groups. *Statistically significant differences were considered when $P<0.05$ (Mann-Whitney $U$ test)

Table 3 Frequency of mDCs producing TNF- $\alpha$, IL-1 $\beta$, IL-6 and IL-12 and amount of each cytokine per cell after stimulation with LPS plus IFN- $\gamma$ in the three studied groups

\begin{tabular}{|c|c|c|c|c|c|c|}
\hline \multirow[t]{2}{*}{$\mathrm{mDCs}$} & \multicolumn{2}{|l|}{ Active SLE } & \multicolumn{2}{|l|}{ Inactive SLE } & \multicolumn{2}{|l|}{ Control } \\
\hline & $\%$ & MFI & $\%$ & MFI & $\%$ & MFI \\
\hline IL- $1 \beta$ & $86.3 \pm 18.4$ & $39.2 \pm 4.3$ & $76.5 \pm 19.0$ & $35.5 \pm 7.1$ & $71.7 \pm 23.7$ & $38.8 \pm 7.1$ \\
\hline IL-6 & $71.8 \pm 28.1$ & $42.4 \pm 16.1$ & $60.1 \pm 25.7$ & $37.7 \pm 14.5$ & $63.3 \pm 19.6$ & $36.0 \pm 6.8$ \\
\hline IL-12 & $68.3 \pm 22.2$ & $29.4 \pm 5.4$ & $57.2 \pm 23.5$ & $28.2 \pm 4.4$ & $53.8 \pm 25.3$ & $32.9 \pm 7.9$ \\
\hline TNF- $\alpha$ & $81.9 \pm 11.8$ & $41.0 \pm 13.0$ & $64.3 \pm 27.7$ & $33.8 \pm 8.6^{\mathrm{a}}$ & $74.9 \pm 20.9$ & $82.2 \pm 46.6$ \\
\hline
\end{tabular}

$\%$ Percentage of positive cells; MFI mean fluorescence intensity of positive cells. Results expressed as mean percentage \pm standard deviation. Statistically significant differences were considered when $P<0.05$ (Mann-Whitney $U$ test): ${ }^{\text {a }}$ Inactive SLE versus Control 
(Table 1). Indeed, our results were in agreement with previous reports demonstrating a lower number of peripheral DCs in SLE patients when compared with healthy subjects [32-34] but disagreed with others reporting significant alterations in the proportion of circulating mDCs/ pDC subtypes [35]. Those apparent discrepancies in the relative distribution of different peripheral DC subpopulations are probably due to the fact that in other works, they did not include a DC subpopulation, defined by us as $\mathrm{CD} 14^{-/ \mathrm{low}} \mathrm{CD} 16^{+} \mathrm{DC}$, among tDCs. In addition, other possible explanations for such observation could be related with the impact of immunosuppressive treatment in haematopoiesis resulting in a decreased output from the bone marrow, namely in active SLE patients rather than a real intrinsic deficiency (increased apoptosis rates and deficiencies during the differentiation and/or activation pathway). Indeed, therapeutic agents that block TNF- $\alpha$, a strong mediator of inflammation capable of exert a wide variety of immunoregulatory and pro-inflammatory actions, namely involved in the maturation of APCs, could in part result in a decreased cellular number observed in patients with active disease. Moreover, SLE patients are characterized by a chronic inflammation combined with greater amounts of cytokines and molecules capable of inducing phenotypic and functional changes in normal DC, preferentially during periods of active disease, may induce peripheral DCs differentiation in SLE patients, resulting in low blood cell numbers through their migration from circulation to lymph nodes and tissues.

Consistent with observations of others [36], our data showed no differences in monocytes number between SLE patients and healthy subjects (Table 1).

To gain insight into the potential role of $\mathrm{PB}$ monocytes and DCs, namely $\mathrm{mDCs}$ and $\mathrm{CD} 14^{-/ \mathrm{low}} \mathrm{CD} 16^{+} \mathrm{DCs}$ on disease onset and progression, we have analysed their functional characteristics according to inflammatory cytokines production, when compared to those from healthy individuals. To address this, we stimulated blood samples from SLE patients with LPS plus IFN- $\gamma$ and studied the cytokine production by these cell populations.

In our study, the frequencies of PB monocytes producing cytokines and the amount of each cytokine produced by those cells without in vitro stimulation were significantly higher in SLE patients, particularly in active SLE patients, when compared with those from healthy subjects, which could be due to an inflammatory microenvironment in the periphery (Table 2). In line with this observations, after stimulation, we found a significantly increase in the frequency of IL-12-producing monocytes in SLE patients with active disease, when compared with healthy individuals, although no significant differences were observed in the amount of each cytokine per monocyte (Table 2).
Concerning the frequency and functional activity of mDCs and $\mathrm{CD} 14^{-/ \text {low }} \mathrm{CD} 16^{+} \mathrm{DCs}$, we found a significantly statistical increase in the percentage of cytokine-producing $\mathrm{CD} 14^{-/ \text {low }} \mathrm{CD} 16^{+} \mathrm{DCs}$ as well as in the amount of cytokine per cell in SLE patients, particularly in those with active disease when compared with healthy subjects (Fig. 2).

Secreted $\mathrm{IgG}$, autoantibodies and antigen-containing IgG immune complexes assume a regulatory role modulating SLE, being implicated in clearance of apoptotic bodies, a source of self immunogen and consequently representing potent amplifiers of autoimmunity [37, 38]. In DCs, the expression of surface receptors that mediates phagocytosis and antibody-dependent cell-mediated cytotoxicity, such as Fc $\gamma$ RIII (CD16), allows them to capture and internalize DNA/anti-DNA immune complexes. Since monocytes and $\mathrm{CD} 14^{- \text {low }} / \mathrm{CD} 16^{+} \mathrm{DC}$ subset display a distinct expression pattern of $F c \gamma R$, their role in phagocytosis will be probably different. Accordingly, our latter observation may be due to the presence of CD16 (lowaffinity $\operatorname{IgG}$ receptor) and lower expression/absence of CD64 (high-affinity $\mathrm{IgG}$ receptor) on $\mathrm{CD} 14^{-/ \text {low }} / \mathrm{CD} 16^{+}$ DCs in opposite to monocytes, suggesting an important role of this DC subset when immune complexes concentration and apoptotic cell fragments are high, as occurs in SLE patients, namely in those with active disease.

Regarding mDCs, we did not found statistical differences in the frequency of cytokine-producing cells and amount of each studied cytokine per cell between SLE patients groups and control group, excepting for the TNF- $\alpha$ amount, which was significantly decreased in inactive SLE patients when compared to control group (Table 3).

Taken together, our results suggest that in SLE patients peripheral blood $\mathrm{CD} 14^{- \text {low }} / \mathrm{CD} 16^{+} \mathrm{DCs}$ and in a lower extension monocytes exhibit a different functional activity, particularly concerning pro-inflammatory cytokine production when responding to external challenges, which could play a particular role in priming $\mathrm{T}$-cell responses and to the maintenance of a higher peripheral inflammatory environment, that could be important in the development and progression of the disease.

\section{References}

1. Mok CC, Lau CS (2003) Pathogenesis of systemic lupus erythematosus. J Clin Pathol 56:481-490. doi:10.1136/jcp.56.7.481

2. Tsubata T (2005) B cell abnormality and autoimmune disorders. Autoimmunity 38:331-337. doi:10.1080/08916930500123959

3. Foster MH (2007) T cells and B cells in lupus nephritis. Semin Nephrol 27:47-58. doi:10.1016/j.semnephrol.2006.09.007

4. Mozaffarian N, Wiedeman AE, Stevens AM (2008) Active systemic lupus erythematosus is associated with failure of antigen-presenting cells to express programmed death ligand-1. 
Rheumatology (Oxford) 47:1335-1341. doi:10.1093/rheumatology/ ken 256

5. Rutella S, De Cristofaro R, Ferraccioli G (2009) Function and dysfunction of dendritic cells in autoimmune rheumatic diseases. Hum Immunol 70:360-373. doi:10.1016/j.humimm.2009.01.023

6. Pertovaara M, Hasan T, Raitala A, Oja SS, Yli-Kerttula U, Korpela $\mathrm{M}$ et al (2007) Indoleamine 2, 3-dioxygenase activity is increased in patients with systemic lupus erythematosus and predicts disease activation in the sunny season. Clin Exp Immunol 150:274-278. doi:10.1111/j.1365-2249.2007.03480.x

7. Grage-Griebenow E, Flad HD, Ernst M (2001) Heterogeneity of human peripheral blood monocyte subsets. J Leukoc Biol 69:11-20

8. Ho CS, Lopez JA, Vuckovic S, Pyke CM, Hockey RL, Hart DN (2001) Surgical and physical stress increases circulating blood dendritic cell counts independently of monocyte counts. Blood 98(1):140-145. doi:10.1182/blood.V98.1.140

9. Fogg DK, Sibon C, Miled C, Jung S, Aucouturier P, Littman DR et al (2006) A clonogenic bone marrow progenitor specific for macrophages and dendritic cells. Science 311:83-87. doi:10.1126/ science. 1117729

10. Leon B, Lopez-Bravo M, Ardavin C (2005) Monocyte-derived dendritic cells. Semin Immunol 17:313-318

11. Almeida J, Bueno C, Alguero MC, Sanchez ML, de Santiago M, Escribano L et al (2001) Comparative analysis of the morphological, cytochemical, immunophenotypical, and functional characteristics of normal human peripheral blood lineage $(-) /$ CD16(+)/HLA-DR(+)/CD14(-/lo) cells, CD14(+) monocytes, and CD16(-) dendritic cells. Clin Immunol 100:325-338. doi: 10.1006/clim.2001.5072

12. Crespo I, Paiva A, Couceiro A, Pimentel P, Orfao A, Regateiro F (2004) Immunophenotypic and functional characterization of cord blood dendritic cells. Stem Cells Dev 13:63-70. doi: $10.1089 / 154732804773099263$

13. Ziegler-Heitbrock HW, Fingerle G, Strobel M, Schraut W, Stelter F, Schutt C et al (1993) The novel subset of CD14+/CD16+ blood monocytes exhibits features of tissue macrophages. Eur $\mathbf{J}$ Immunol 23:2053-2058. doi:10.1002/eji.1830230902

14. Thomas R, Lipsky PE (1994) Human peripheral blood dendritic cell subsets. Isolation and characterization of precursor and mature antigen-presenting cells. J Immunol 153:4016-4028

15. Ziegler-Heitbrock HW (1996) Heterogeneity of human blood monocytes: the CD14 + CD16+ subpopulation. Immunol Today 17:424-428. doi:10.1016/0167-5699(96)10029-3

16. Kubach J, Becker C, Schmitt E, Steinbrink K, Huter E, Tuettenberg A et al (2005) Dendritic cells: sentinels of immunity and tolerance. Int J Hematol 81:197-203. doi:10.1532/IJH97.04165

17. Palucka K, Banchereau J (1999) Dendritic cells: a link between innate and adaptive immunity. J Clin Immunol 19:12-25. doi: 10.1023/A:1020558317162

18. Hawiger D, Inaba K, Dorsett Y, Guo M, Mahnke K, Rivera M et al (2001) Dendritic cells induce peripheral T cell unresponsiveness under steady state conditions in vivo. J Exp Med 194:769-779. doi:10.1084/jem.194.6.769

19. Curti A, Trabanelli S, Salvestrini V, Baccarani M, Lemoli RM (2009) The role of indoleamine 2, 3-dioxygenase in the induction of immune tolerance: focus on hematology. Blood 113: 2394-2401. doi:10.1182/blood-2008-07-144485

20. Theofilopoulos AN, Koundouris S, Kono DH, Lawson BR (2001) The role of IFN-gamma in systemic lupus erythematosus: a challenge to the Th1/Th2 paradigm in autoimmunity. Arthritis Res 3:136-141. doi:10.1186/ar290

21. Ding D, Mehta H, McCune WJ, Kaplan MJ (2006) Aberrant phenotype and function of myeloid dendritic cells in systemic lupus erythematosus. J Immunol 177:5878-5889
22. Crispin JC, Alcocer-Varela J (2007) The role myeloid dendritic cells play in the pathogenesis of systemic lupus erythematosus. Autoimmun Rev 6:450-456. doi:10.1016/j.autrev.2007.01.014

23. Robak E, Smolewski P, Wozniacka A, Sysa-Jedrzejowska A, Stepien H, Robak T (2004) Relationship between peripheral blood dendritic cells and cytokines involved in the pathogenesis of systemic lupus erythematosus. Eur Cytokine Netw 15:222-230

24. Hochberg MC (1997) Updating the American College of Rheumatology revised criteria for the classification of systemic lupus erythematosus. Arthritis Rheum 40:1725

25. Tan EM, Cohen AS, Fries JF, Masi AT, McShane DJ, Rothfield NF et al (1982) The 1982 revised criteria for the classification of systemic lupus erythematosus. Arthritis Rheum 25:1271-1277

26. Bombardier C, Gladman DD, Urowitz MB, Caron D, Chang CH (1992) Derivation of the SLEDAI. A disease activity index for lupus patients. The Committee on Prognosis Studies in SLE. Arthritis Rheum 35:630-640. doi:10.1002/art.1780350606

27. Gladman DD, Ibanez D, Urowitz MB (2002) Systemic lupus erythematosus disease activity index 2000. J Rheumatol 29: 288-291

28. Griffiths B, Mosca M, Gordon C (2005) Assessment of patients with systemic lupus erythematosus and the use of lupus disease activity indices. Best Pract Res Clin Rheumatol 19:685-708. doi: 10.1016/j.berh.2005.03.010

29. Ronnblom L, Alm GV, Eloranta ML (2009) Type I interferon and lupus. Curr Opin Rheumatol 21(5):471-477. doi:10.1097/BOR. 0b013e32832e089e

30. Gigante A, Amoroso D, Ferri F, Gianni C, Coppolino G, Papa A et al (2006) Systemic lupus erythematosus and renal involvement: which role of citokines expression? Eur Rev Med Pharmacol Sci 10:223-228

31. Kulkarni O, Anders HJ (2008) Chemokines in lupus nephritis. Front Biosci 13:3312-3320

32. Cederblad B, Blomberg S, Vallin H, Perers A, Alm GV, Ronnblom L (1998) Patients with systemic lupus erythematosus have reduced numbers of circulating natural interferon-alpha-producing cells. J Autoimmun 11:465-470. doi:10.1006/jaut.1998. 0215

33. Vallin H, Blomberg S, Alm GV, Cederblad B, Ronnblom L (1999) Patients with systemic lupus erythematosus (SLE) have a circulating inducer of interferon-alpha (IFN-alpha) production acting on leucocytes resembling immature dendritic cells. Clin Exp Immunol 115:196-202. doi:10.1046/j.1365-2249.1999.00772.x

34. Scheinecker C, Zwolfer B, Koller M, Manner G, Smolen JS (2001) Alterations of dendritic cells in systemic lupus erythematosus: phenotypic and functional deficiencies. Arthritis Rheum 44:856-865. doi:10.1002/1529-0131(200104)44:4<856:AID-ANR142> 3.0.CO;2-A

35. Jin O, Kavikondala S, Sun L, Fu R, Mok MY, Chan A et al (2008) Systemic lupus erythematosus patients have increased number of circulating plasmacytoid dendritic cells, but decreased myeloid dendritic cells with deficient CD83 expression. Lupus 17:654-662. doi:10.1177/0961203308089410

36. Li Y, Lee PY, Sobel ES, Narain S, Satoh M, Segal MS et al (2009) Increased expression of FcgammaRI/CD64 on circulating monocytes parallels ongoing inflammation and nephritis in lupus. Arthritis Res 11:R6. doi:10.1186/ar2590

37. Means TK, Latz E, Hayashi F, Murali MR, Golenbock DT, Luster AD (2005) Human lupus autoantibody-DNA complexes activate DCs through cooperation of CD32 and TLR9. J Clin Invest 115:407-417. doi:10.1172/JCI200523025

38. Stanilova SA, Slavov ES (2001) Comparative study of circulating immune complexes quantity detection by three assays-CIFELISA, C1q-ELISA and anti-C3 ELISA. J Immunol Methods 253:13-21. doi:10.1016/S0022-1759(01)00370-2 